\title{
Molecular imaging and targeted therapies in oncology: New concepts in treatment response assessment. A collection of cases
}

\author{
M.A.PANTALEO ${ }^{1}$, M.NANNINI ${ }^{1}$, E. LOPCI ${ }^{2}$, P.CASTELLUCCI ${ }^{2}$, A. MALEDDU $^{1}$, F. $_{\text {LODI }}{ }^{3}$, C. NANNI $^{2}$, \\ V. ALLEGRI ${ }^{2}$, M. ASTORINO ${ }^{1}$, G. BRANDI ${ }^{1}$, M.DI BATTISTA ${ }^{1}$, S. BOSCHI ${ }^{3}$, S. FANTI ${ }^{2}$ and G. BIASCO ${ }^{1}$ \\ ${ }^{1}$ Institute of Hematology and Medical Oncology 'L\&A Seragnoli'; ${ }^{2}$ Nuclear Medicine Service; ${ }^{3}$ PET \\ Radiopharmacy Nuclear Medicine Service, Sant'Orsola-Malpighi Hospital, University of Bologna, Bologna, Italy
}

Received February 25, 2008; Accepted April 14, 2008

DOI: 10.3892/ijo_00000026

\begin{abstract}
The widespread use of several new non-cytotoxic drugs and the significant improvements in functional imaging highlights a number of difficulties in monitoring, interpreting and predicting treatment response in clinical practice. Certain guidelines for disease assessment after therapy are already available: the traditional Response Evaluation Criteria in Solid Tumours guidelines based on tumour size variations using conventional imaging technologies, the recent combined method developed by Choi and colleagues in gastrointestinal stromal tumour treated with tyrosine kinase inhibitors based on tumour density variations using computed tomography (CT), and the European Organization for Research and Treatment of Cancer criteria based on tumour glucose metabolism variations using fluorodeoxyglucose (FDG) positron emission tomography (PET). At the moment combined PET/CT response criteria are still not available. A number of new PET compounds other than FDG are also currently being developed to visualize specific cellular and molecular tumour pathways but their role in assessment and prediction of cancer treatment response has not yet been thoroughly investigated in a large series. However, in clinical practice many oncologists treat cancer patients with targeted therapies or chemotherapy and evaluate the response using conventional or functional imaging without appropriate and standardized guidelines. The aim of this study was to present a selection of clinical cases that illustrate the usefulness of new PET tracers and efficacy evaluation of new drugs. In the era of molecular imaging and molecular therapies, these cases highlight the urgency to develop new criteria for treatment assessment and
\end{abstract}

Correspondence to: Dr M.A. Pantaleo, University of Bologna, Institute of Hematology and Medical Oncology 'L\&A Seragnoli', Sant'Orsola-Malpighi Hospital, Via Massarenti 9, I-40138 Bologna, Italy

E-mail: maria.pantaleo@unibo.it

Key words: PET, ${ }^{11} \mathrm{C}$-choline PET, ${ }^{11} \mathrm{C}$-methionine PET, ${ }^{68} \mathrm{Ga}-$ DOTA-NOC PET, sunitinib, bevacizumab, Response Evaluation Criteria in Solid Tumours the exigency of correctly interpreting the biological information obtained from new technologies, and introduce new concepts that require further investigation in clinical trials.

\section{Introduction}

The development and the introduction to clinical practice of several new drugs and new therapeutical strategies specifically directed to molecular targets has revolutionized medical treatments in oncology (1). However, the widespread use of new non-cytotoxic drugs highlights the difficulty of monitoring their therapeutical efficacy in clinical practice for many oncologists. In solid tumours, certain criteria are available for the assessment of anticancer treatment activity (Table I). The Response Evaluation Criteria in Solid Tumours (RECIST) guidelines are traditionally considered the standard method both in clinical research and practice. These use dimensional criteria for the evaluation of lesions and do not provide information on biological or metabolic variations (2). Recently, a combined method with computed tomography (CT) was introduced by Choi and colleagues for response assessment in gastrointestinal stromal tumour (GIST) treated with tyrosine kinase (TK) inhibitors (imatinib, sunitinib) (3). The widespread use of functional imaging of solid tumours by positron emission tomography (PET) with $18 \mathrm{~F}$-fluorodeoxyglucose (FDG) induced the European Organization for Research and Treatment of Cancer (EORTC) to develop the PET guidelines for treatment assessment in solid tumours, but at the moment combined PET/CT response criteria are still not available (4) (Table I).

While the role of FDG PET in monitoring and predicting chemotherapy efficacy has been widely reported over the last few years, few studies are available on new targeted therapies for solid tumours except in GISTs. The medical treatment of GISTs represents a model in oncology for both the dramatic success of molecular drugs with imatinib and sunitinib and for the importance of introducing the functional response evaluation with FDG PET to clinical practice (5-9). In other types of cancer, few data are available. In a small series of patients with metastatic colorectal carcinoma treated with irinotecan and bevacizumab, FDG PET predicted necrosis of liver metastases at pathological evaluation in $70 \%$ of cases (10). The same results were reported in patients treated with bevacizumab and chemoradiotherapy as neoadjuvant 
Table I. Criteria for treatment assessment in solid tumours and lymphomas.

Solid tumors

\begin{tabular}{|c|c|c|c|c|}
\hline Definitions & Complete response (CR) & Partial response (PR) & Stable disease (SD) & Progressive disease (PD) \\
\hline \multicolumn{5}{|c|}{ Morphological } \\
\hline WHO & $\begin{array}{l}\text { Complete disappearance } \\
\text { of all lesions. }\end{array}$ & $\begin{array}{l}\text { At least } 50 \% \text { decrease in } \\
\text { tumour size. }\end{array}$ & $\begin{array}{l}\text { Meets neither PR nor PD } \\
\text { criteria. }\end{array}$ & $\begin{array}{l}>25 \% \text { increase of at least } \\
\text { one lesion or new lesions. }\end{array}$ \\
\hline RECIST & $\begin{array}{l}\text { Complete disappearance } \\
\text { of all lesions. }\end{array}$ & $\begin{array}{l}\text { At least } 30 \% \text { decrease in } \\
\text { tumour size. }\end{array}$ & $\begin{array}{l}\text { Meets neither PR nor PD } \\
\text { criteria. }\end{array}$ & $>20 \%$ increase in size. \\
\hline \multicolumn{5}{|l|}{ Metabolic } \\
\hline EORTC & $\begin{array}{l}\text { Complete resolution of } \\
{\left[{ }^{18} \mathrm{~F}\right] \text {-FDG uptake within }} \\
\text { the tumour volume so that } \\
\text { it is indistinguishable } \\
\text { from surrounding normal } \\
\text { tissue. }\end{array}$ & $\begin{array}{l}\text { Reduction of a minimum } \\
\text { of } 15-25 \% \text { in tumour } \\
{\left[{ }^{18} \mathrm{~F}\right] \text {-FDG SUV after one }} \\
\text { cycle of CT and }>25 \% \\
\text { after more than one } \\
\text { treatment cycle. }\end{array}$ & $\begin{array}{l}\text { An increase in tumour } \\
{\left[{ }^{18} \mathrm{~F}\right]-\mathrm{FDG} \text { SUV of }<25 \%} \\
\text { or a decrease of }<15 \% \\
\text { and no visible increase in } \\
\text { extent of }\left[{ }^{18} \mathrm{~F}\right]-\mathrm{FDG} \\
\text { tumour uptake ( }>20 \% \text { in } \\
\text { the longest dimension). }\end{array}$ & $\begin{array}{l}\text { An increase in }\left[{ }^{18} \mathrm{~F}\right]-\mathrm{FDG} \\
\text { tumour SUV of }>25 \% \\
\text { within the tumour region } \\
\text { defined on the baseline scan } \\
\text { visible increase in the extent } \\
\text { of }\left[{ }^{18} \mathrm{~F}\right]-\mathrm{FDG} \text { tumour uptake } \\
\text { or appearance of new } \\
{\left[{ }^{18} \mathrm{~F}\right]-\mathrm{FDG} \text { uptake in }} \\
\text { metastatic lesions. }\end{array}$ \\
\hline \multicolumn{5}{|c|}{$\begin{array}{l}\text { Combined } \\
\text { dimensional } \\
\text { and functional }\end{array}$} \\
\hline $\mathrm{CHOI}$ & $\begin{array}{l}\text { Disappearance of all } \\
\text { lesions. No new lesions. }\end{array}$ & $\begin{array}{l}\text { A decrease in size of } \\
\geq 10 \% \text { or a decrease in } \\
\text { tumour density (HU) } \\
\geq 15 \% \text { in CT. No new } \\
\text { lesions. No obvious } \\
\text { progression of non- } \\
\text { measurable disease. }\end{array}$ & $\begin{array}{l}\text { Does not meet the criteria } \\
\text { for CR, PR or PD. No } \\
\text { symptomatic deterioration } \\
\text { attributed to tumour } \\
\text { progression. }\end{array}$ & $\begin{array}{l}\text { An increase in tumour size } \\
\text { of } \geq 10 \% \text { and does not meet } \\
\text { criteria of PR for tumour } \\
\text { density (HU) in CT. New } \\
\text { lesions. New intra-tumoural } \\
\text { nodules or increase in the } \\
\text { size of the existing intra- } \\
\text { tumoural nodules. }\end{array}$ \\
\hline
\end{tabular}

WHO, World Health Organization; RECIST, Response Evaluation Criteria in Solid Tumours; EORTC, European Organization for Research and Treatment of Cancer; CHOI, Choi et al (3).

treatment for rectal cancer (11). Preliminary results have been reported on the decrement of metabolic activity after administration of lapatinib which is an inhibitor of epidermal growth factor receptors (Erb-B1/EGFr and Erb-B2) in patients who experienced clinical benefits from treatment (12). Preclinical studies have shown that treatment with TK inhibitors of EGFr results in a reduction of glucose metabolism that may predict tumour response $(13,14)$. Some clinical data has recently been reported in relation to this, in 5 patients with lung cancer treated with gefitinib, and in 22 patients with gastric cancer treated with cetuximab $(15,16)$.

Along with the development of innovative strategies in cancer therapy over the few last years, significant improvements have been made in functional imaging. A number of new PET compounds other than FDG are also currently being developed to visualize specific cellular and molecular tumour pathways such as ${ }^{68} \mathrm{Ga}$-DOTA-TOC, ${ }^{68} \mathrm{Ga}$-DOTANOC, ${ }^{11} \mathrm{C}$-choline, ${ }^{11} \mathrm{C}$-acetate, ${ }^{11} \mathrm{C}$-methionine, ${ }^{18} \mathrm{~F}$-FLT and others (17). However, until now these new PET/CT tracers have mostly been used for cancer detection and their specific role in the assessment and prediction of cancer treatment response has not yet been thoroughly investigated in a large series.

As a consequence, despite this progress in anticancer treatments and in imaging technologies, in most worldwide clinical trials therapeutical efficacy is still evaluated only with dimensional criteria or glucose metabolism variations.

The aim of this study was to present selected clinical cases that elucidate certain issues regarding the significance of functional imaging information in treatment assessment and prediction for new non-cytotoxic drugs, and the usefulness of new PET tracers in the efficacy evaluation of chemotherapy and/or molecular therapies.

\section{Case presentations}

\section{Case presentation 1}

FDG PET uptake variation supports the continuous administration of sunitinib in metastatic renal carcinoma $(R C C)$. A 64-year-old male was submitted to left nefrectomy in 1997, for renal clear cell carcinoma (RCC). In November 2006 he developed a recurrence with liver, lung and bone 

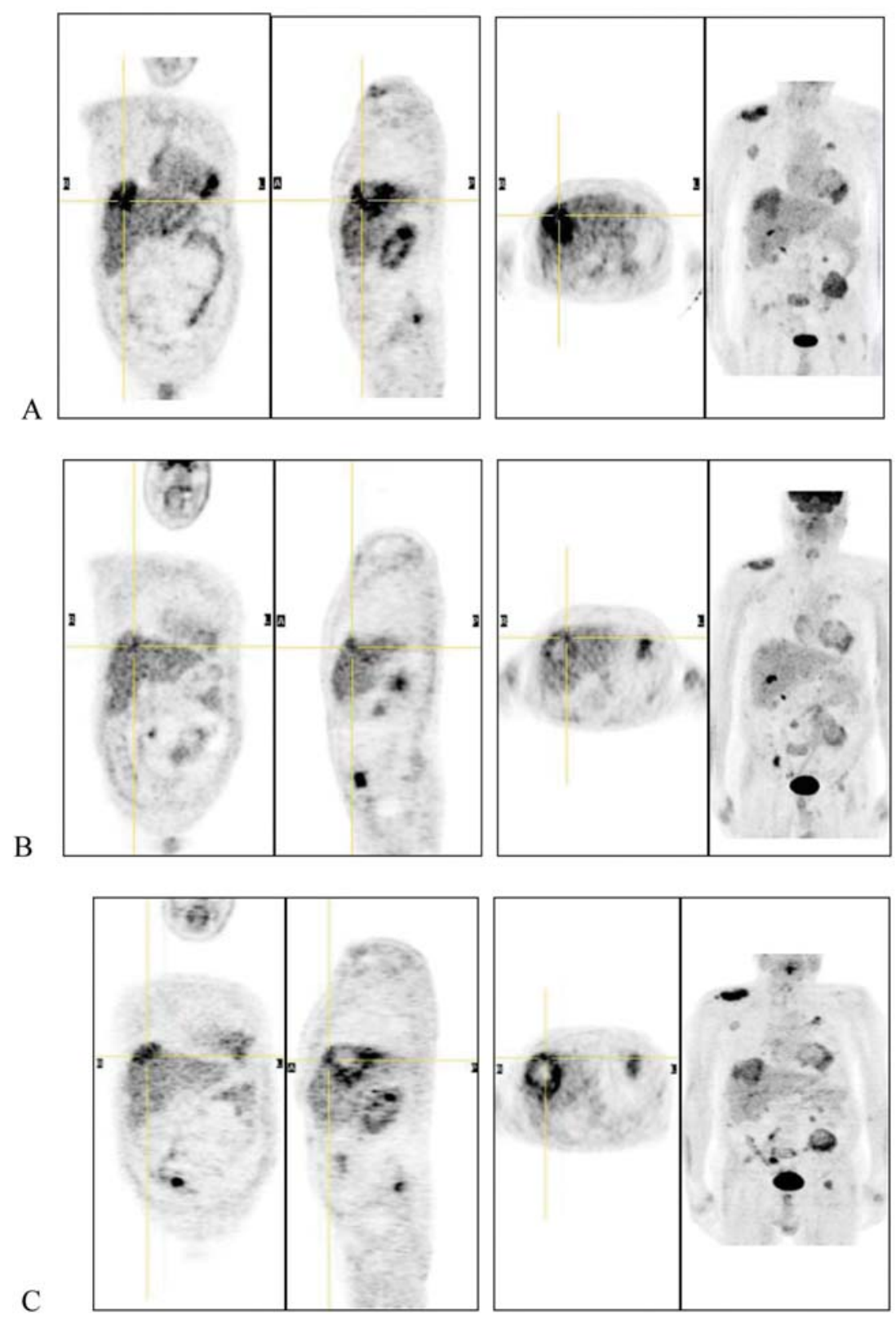

Figure 1. FDG PET scan in mRCC treated with sunitinib (50 mg/day, 4 weeks on/2 weeks off). (A) PET images before treatment: lung, liver, bone, lymph nodes, and muscle metastases. (B) PET images after 3 weeks of treatment: reduction of glucose uptake (especially in liver metastases). (C) PET images after 2 weeks treatment-off period: increase of glucose uptake (especially in liver metastases).

metastases evaluated by CT. He was treated with capecitabine as a first-line therapy for 2 months, but in February 2007 a progression of disease occurred. An FDG PET/CT scan showed widespread metastatic disease, involving lung, liver, skeletal system, lymph nodes, and muscles (SUVmax 6.0) (Fig. 1A). He started treatment with sunitinib $50 \mathrm{mg} /$ day, 4 weeks on/ 2 weeks off schedule. After three weeks of therapy, an FDG PET/CT control showed a reduction of the fixation gradient of all metastatic lesions (SUVmax 3.8) (Fig. 1B). During the two-week treatment-off period, a second F-FDG PET/CT control showed an increase of metabolic activity of all the known lesions (Fig. 1C). The patient continued to receive Sunitinib, but died due to heart toxicity two months later.

Discussion. FDG-PET has mostly shown low sensitivity in metastatic RCC (mRCC) (18). However in a small number of patients FDG uptake is positive and in these cases FDG-PET represents a valid imaging procedure for the detection of distant metastases from RCC because it has an overall specificity and positive predictive value of $100 \%$ (18). In our patient, the FDG PET/CT was positive in multiple metastatic sites; consequently we used this technology to monitor the treatment with sunitinib.

Sunitinib is an oral multitargeted inhibitor of vascular endothelial growth factor receptor (VEGFr) and plateletderived growth factor receptor (PDGFr) and at present represents the standard treatment for metastatic RCC, both in front-line and second-line therapy (19). In a recent randomized phase III trial that compared sunitinib efficacy with the traditional IFN $\alpha$ and was conducted in 750 previously untreated patients, sunitinib at a daily dose of $50 \mathrm{mg}$ (4 weeks on/ 2 weeks off) has been shown to lead to longer progressionfree survival (11.0 vs 5.0 months, $\mathrm{P}<0.001)$, higher objective 
response rate ( 31 vs $6 \%, \mathrm{P}<0.001)$, and a better global quality of life than IFN $\alpha$.

Sunitinib has also been approved as a second-line therapy for the treatment of gastrointestinal stromal tumours (GISTs) for imatinib-resistant or -intolerant patients (9). In this setting, the anti-target activity was clearly demonstrated by an early significant metabolic response detected by FDG PET imaging and by rebound of FDG uptake after withdrawal of the drug (20). The strict correlation between sunitinib therapy and the tumour metabolic response and especially the early increment of FDG uptake during the period off the drug in GISTs, supported the evaluation of continuous $37.5 \mathrm{mg}$ daily administration of sunitinib $(21,22)$. At present, continuous administration is feasible, but mature data related to the outcome of the patients are not yet available.

Our clinical case of a patient with $\mathrm{mRCC}$ treated with sunitinib similarly showed an early FDG PET metabolic response for all metastatic lesions and a metabolic disease progression during the treatment-off period. Therefore, this case raises two important clinical points. Firstly, the significance of biological information obtained by a glucose metabolism variation in $\mathrm{mRCC}$ needs to be determined. Further studies are required to define the role of FDG PET in the early assessment of sunitinib therapy response compared to the traditional dimensional data of CT imaging in order to select those patients who may benefit more from molecular targeted treatment. Secondly, our case may support further phase III randomized clinical trials that are required to assess sunitinib $37.5 \mathrm{mg} /$ day continuous administration in mRCC treatment in comparison to $50 \mathrm{mg} /$ day 4 weeks on/2 weeks off in order to improve patient outcome.

\section{Case presentation 2}

Use of ${ }^{11} \mathrm{C}$-choline PET/CT for treatment response evaluation in metastatic prostate cancer. A 67-year-old male underwent total prostatectomy for a prostate cancer in 1998. Six years later, he developed recurrence with multiple bone metastatic lesions and local relapse and he was treated with hormonal therapy and radiotherapy. In September 2006, the disease became hormonal-treatment refractory after three lines of hormonal therapy. An increment of serum PSA level (149.0 $\mathrm{ng} / \mathrm{ml}$, previously $7.0 \mathrm{ng} / \mathrm{ml}$ ) occurred and an evaluation with total bone scan and ${ }^{11} \mathrm{C}$-choline PET/CT scan showed multiple metastatic lesions at the right collar bone, fifth right rib, L1 and pelvis (Fig. 2A). The patient therefore, was treated with five cycles of chemotherapy (three-weekly Taxotere) plus zoledronic acid, until February 2007. A posttreatment ${ }^{11} \mathrm{C}$-choline PET/CT showed a reduction of the extension and gradient of all bone lesions, according to the decrement of serum PSA level (44.99 mg/ml) (Fig. 2B). In contrast, the total bone scan was stable. Considering this partial metabolic response, the patient continued to receive the same treatment for other four cycles until June with stable disease both for imaging and serum level of PSA $(40.0 \mathrm{mg} / \mathrm{ml})$ (Fig. 2C). Progression of disease occurred in December 2007, corresponding with an increase of PSA level $(148.0 \mathrm{mg} / \mathrm{ml})$ (Fig. 2D).

Discussion. At present, several studies are in progress to define the role in clinical practice of ${ }^{11} \mathrm{C}$-choline PET/CT for the diagnosis of prostate cancer and for the detection of local and distant recurrence (23-30). Bone metastases can be visualised by ${ }^{11} \mathrm{C}$-choline $\mathrm{PET}$ even in patients with negative FDG PET (31). This increased interest in clinical research mostly depends on the low sensitivity and specificity that FDG PET has shown in diagnosing primary tumours due to the low proliferating rate and low glucose utilization, and also due to the physiological urinary excretion and uptake in inflammatory areas, of FDG. Picchio and colleagues reported that ${ }^{11} \mathrm{C}$-choline PET/CT is complementary to standard imaging technologies (CT, MRI, bone scan) and superior to FDG PET for restaging of prostate cancer patients with increasing serum PSA levels (32). No conclusive data have been reported on ${ }^{11} \mathrm{C}$-choline $\mathrm{PET} / \mathrm{CT}$ for the detection of distant metastases nor on the comparison to ${ }^{18} \mathrm{~F}$-choline PET/CT (33).

In our clinical case, a patient with metastatic prostate cancer was treated with Taxotere and zoledronic acid and was evaluated with ${ }^{11} \mathrm{C}$-choline $\mathrm{PET} / \mathrm{CT}$ pre- and post-therapy. The examinations indicated a partial remission of disease which was in accordance with the decrement in serum PSA level, while total bone scan showed stable disease. The correlation between metabolic activity and serum PSA levels suggests that ${ }^{11} \mathrm{C}$-choline PET/CT may be useful for monitoring treatment in patients with metastatic prostate cancer. Furthermore, ${ }^{11} \mathrm{C}$-choline PET/CT may be more predictive of treatment response than bone scan in case of bone metastases because it offers more specific data about the metabolic activity of disease and not only about the bone remodelling. This approach may be translated to the evaluation of treatment response of other metastatic sites and should be further investigated in future clinical trials. Up until now the usefulness of ${ }^{11} \mathrm{C}$-choline PET/CT in treatment response has only been studied to evaluate hormonal therapy in patients with primary tumours. However, in our opinion it should also be investigated in two clinical scenarios: in a metastatic setting and also for chemotherapy assessment in patients with hormonal refractory prostate cancer.

\section{Case presentations 3 and 4}

Assessment of response to bevacizumab based therapy in metastatic colorectal cancer with FDG PET/CT. A 68-yearold man underwent a total emicolectomy for a distal colon cancer in September 2006, and was subsequently treated with adjuvant chemotherapy based on 5-fluorouracil, leucovorin and oxaliplatin regimen (FOLFOX-4). In June 2007, a recurrence of disease occurred. A pre-therapy FDG PET/CT scan showed multiple metastatic hepatic lesions, also confirmed by abdominal MRI (Fig. 3A). The patient was treated with six cycles of 5-fluorouracil, leucovorin and irinotecan (FOLFIRI) plus bevacizumab until September 2007. At the end of treatment an FDG PET/CT showed a complete metabolic response and a $\mathrm{CT}$ showed a dimensional reduction of all hepatic lesions (Fig. 3B). The patient continues to receive the same treatment.

In May 2007, a 43-year-old male was diagnosed with left colon cancer with synchronous multiple liver metastases by CT. Firstly, he underwent left emicolectomy and then he was proposed for systemic chemotherapy with FOLFIRI plus bevacizumab as first-line therapy. A pre-treatment ${ }^{18} \mathrm{~F}-\mathrm{FDG}$ $\mathrm{PET} / \mathrm{CT}$ confirmed the presence of the known hepatic lesions 


\section{$\begin{array}{lll}\text { A. PSA: } 149.0 \mathrm{ng} / \mathrm{ml} & \text { B. PSA: } 44.99 \mathrm{ng} / \mathrm{ml}\end{array}$}

C. PSA: $40.0 \mathrm{ng} / \mathrm{ml}$

D. PSA: $148.0 \mathrm{ng} / \mathrm{ml}$
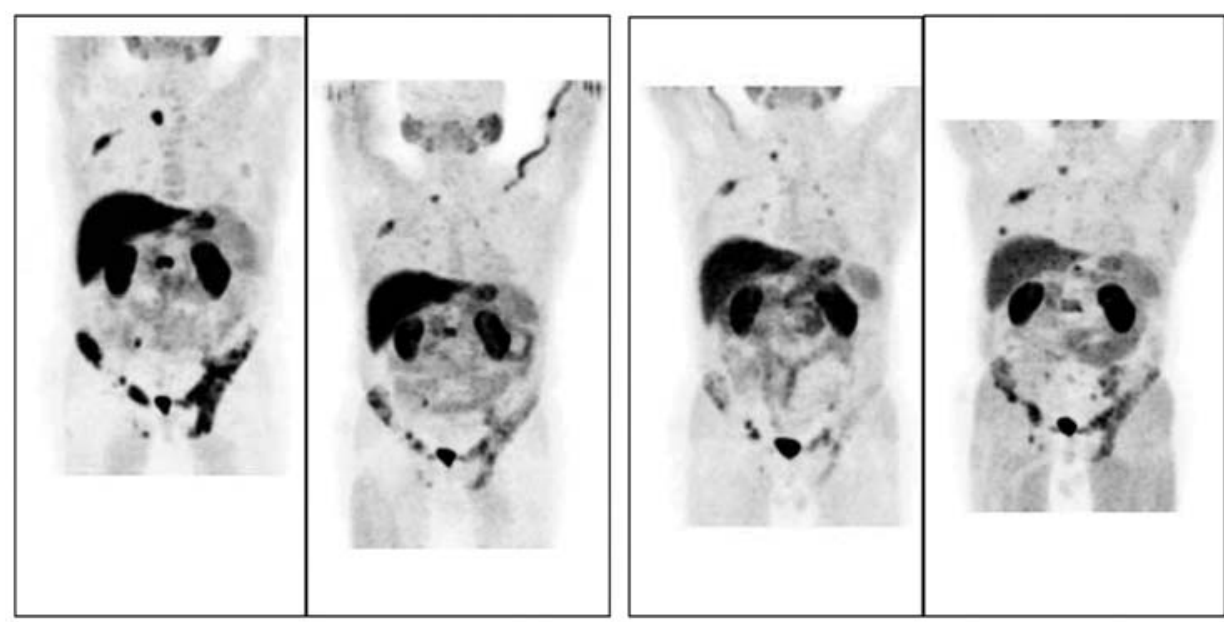

Figure 2. ${ }^{11} \mathrm{C}$-choline PET/CT scan according to PSA levels in prostate cancer treated with Taxotere and zoledronic acid. (A) PET images before treatment: multiple metastatic bone lesions. (B) PET images after 3 cycles of chemotherapy: reduction of extension and glucose uptake of all bone lesions. (C) PET images after another 4 cycles of chemotherapy: stable disease. (D) PET images after another 3 cycles of chemotherapy: progression disease.

A
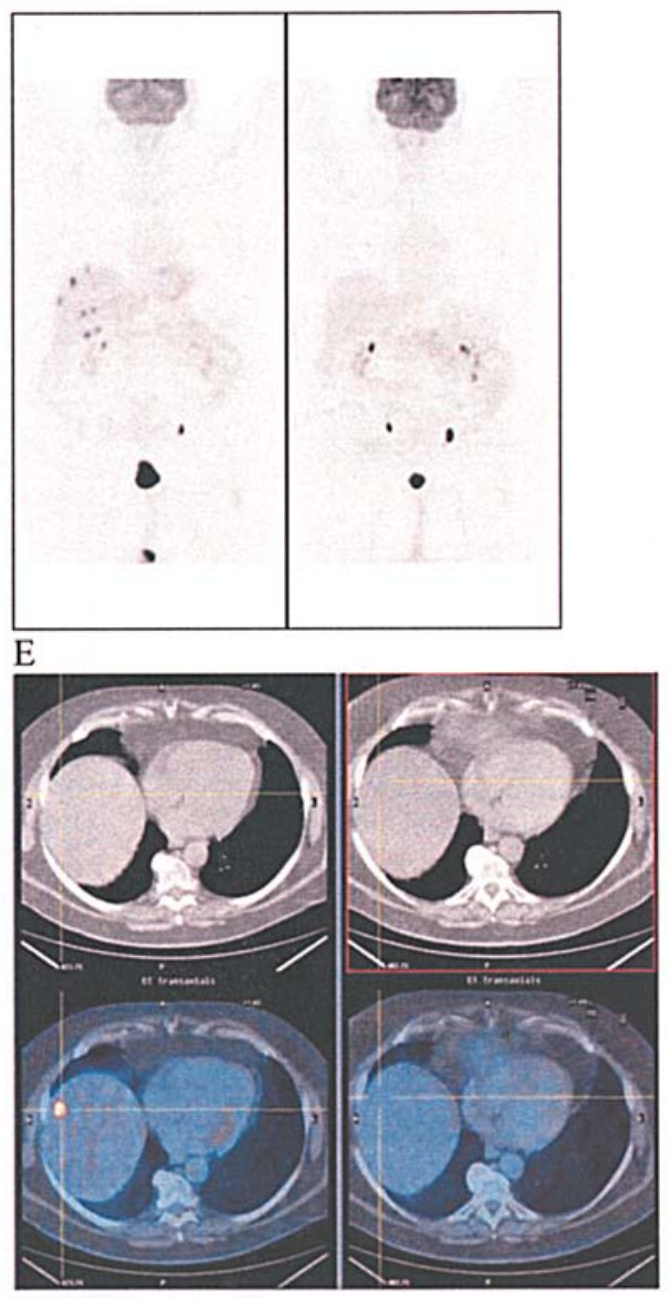

$\mathrm{C}$

$\mathrm{D}$

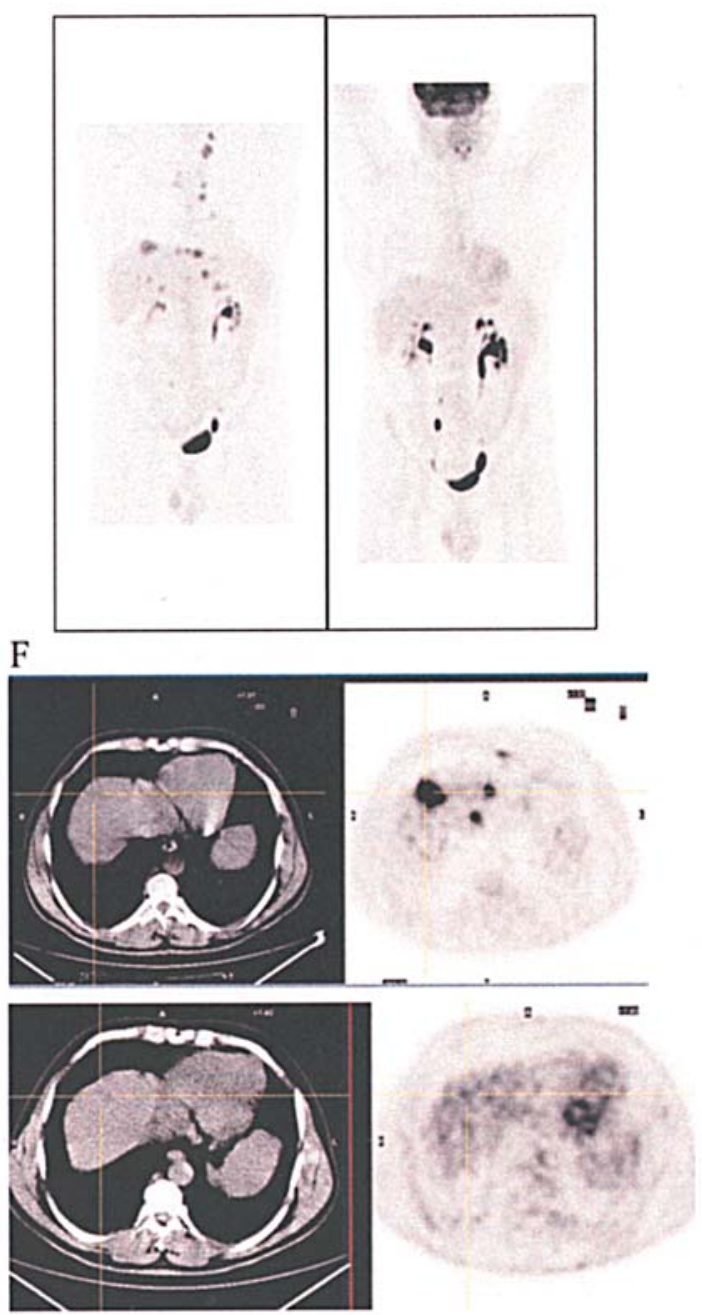

Figure 3. FDG PET/CT scan in mCRC treated with bevacizumab and FOLFIRI. (A) PET images before treatment: multiple metastatic hepatic lesions. (B) PET images after treatment: complete response. (C) PET images before treatment: multiple metastatic hepatic lesions, lymph nodes and suspected left lung lesion. (D) PET images after treatment: complete response (only mild uptake in the liver). (E) Transaxial CT and PET/CT images showing hepatic metastases before (left column) and after treatment (right column). (F) Transaxial CT and PET images: hepatic metastases before (upper row) and after treatment (lower row). 
associated with a suspected left lung lesion and several pathological lymph nodes (Fig. 3C). The patient was treated with six cycles of chemotherapy until September 2007. A new FDG PET/CT evaluation showed a complete metabolic response and a $\mathrm{CT}$ showed a partial remission of disease (Fig. 3D). The patient was proposed for surgery.

Discussion. Bevacizumab is a recombinant humanized monoclonal antibody against VEGF, approved as a front-line treatment of metastatic colorectal cancer (mCRC) in association with irinotecan, bolus fluorouracil and leucovorin (IFL regimen) (34). In a phase III trial that compared IFL with or without bevacizumab in previously untreated patients, the combination regimen showed a longer median overall survival (18.3 vs 15.1 months), a longer median progressionfree survival (8.8 vs 6.8 months) and higher overall response rates (40.0 vs $37.0 \%$ ) than IFL regimen alone, with an acceptable safety profile (34). Moreover, bevacizumab has also been efficacious in other types of cancer such as lung, renal and breast cancer $(35,36)$.

Bevacizumab does not have a cytotoxic activity and may not lead to lesion shrinkage. Its main property is the inhibition of angiogenesis so as a consequence we can first expect a modification of the vascular pattern of the metastases and secondly the modification of dimensions. New technologies such as MRI and contrast enhanced ultrasound (CEUS) have been investigated for their promising usefulness in VEGF expression detection and for their application in monitoring VEGF signalling pathway inhibition (37). In clinical practice, bevacizumab is basically used in combination with chemotherapy and activity is globally evaluated using standard technologies. Regarding FDG PET, a few small-scale studies have evaluated the possible contribution of FDG PET/CT as a surrogate marker to assess bevacizumab-based therapy response of colorectal liver metastases and primary rectal cancer $(10,11)$. In both studies, FDG PET seemed to be useful for predicting the pathological responses. Recently, fluorothymidine (FLT) PET has been studied in patients with recurrent gliomas treated with bevacizumab and irinotecan and seems to be predictive of overall survival (40). As a consequence, the role of FDG PET/CT in predicting treatment response in colorectal cancer has already been thoroughly investigated especially for regimens with chemotherapy only and also for regimens combining chemotherapy and bevacizumab; in contrast, its role in assessment of treatment response is still controversial and has not been properly studied $(10,11,38)$. At present, no standardized criteria or guidelines are available. In clinical practice most oncologists continue to use conventional imaging technologies (CT, MRI) that basically provide dimensional data of disease. Today, one of the most interesting clinical issues in oncology is that the mechanisms of action of new targeted drugs would probably require innovative molecular or functional imaging technologies for the evaluation of their activity, and that at the same time as these technologies are available and used in practice we are still unable to interpret the information provided.

FDG PET/CT may give clinicians different information: only functional information following EORTC criteria as in our clinical cases of two patients with mCRC treated with FOLFIRI plus bevacizumab who showed a 'complete' response (CR) (Fig. 3A-F), or combined functional and dimensional information, but no standardized criteria are available at this stage to interpret the results. Consequently, we can classify a case as 'complete response' when both metabolic and dimensional findings disappear, but how the response should be classified when functional indications disappear without lesion shrinkage is unclear; it could probably be classified as 'stable' or 'partial' response. However the clinical implications of these data are still unknown. The same considerations may be translated to the 'progression of disease' concept. As it has also been demonstrated in GISTs after imatinib administration or in solid tumours after chemotherapy, the reduction of SUV is associated with a better clinical outcome, and the PET metabolic response after bevacizumab will probably also be able to predict treatment efficacy beforehand $(8,39)$. The data provided by these technologies suggest that the functional response probably precedes the dimensional one. However further prospective clinical trials are required in order to better define its role in clinical practice and in order to establish standardized response evaluation criteria to this biological drug or response classifications according to patient clinical outcome.

\section{Case presentation 5}

${ }^{11} \mathrm{C}$-methionine PET role in inconclusive conventional imaging report of low-grade glioma. A 65-year-old female presented at our Nuclear Medicine Division for an in-depth diagnostic evaluation. She had complained of hydrocephalic symptoms for several months, associated with sporadic seizure episodes. The encephalic MRI study showed an opercular round lesion interesting the right cerebral hemisphere with hyperintese signal on T2-weighted images and faint uneven contrast medium recruitment (Fig. 4A). Results were judged to be of an unclear nature and therefore no conclusive report was made. We decided to perform a ${ }^{11} \mathrm{C}$-methionine PET (MET PET) scan. Our study revealed an increased uptake of the tracer interesting the reported lesion, suggestive of a malignant lesion, compatible with glioma (Fig. 4B). The histological examination after stereotactic biopsy confirmed a grade II astrocytoma.

Discussion. Supratentorial low-grade astrocytomas are common brain tumours affecting principally male individuals with a male-to-female ratio of $2: 1$. Increased intracranial pressure, which is observed in $50-75 \%$ of patients, causes the most common initial presentations. There may also be seizures (25-50\% of patients), headache, vomiting, changes in behaviour, and changes in mental status (40).

Conventional imaging methods, including $\mathrm{CT}$ and especially MRI, provide excellent anatomical information, reaching a $65-100 \%$ sensitivity in contrast-enhanced images and a variable specificity, but are deficient in differentiating tumours from other non-pathological findings, as well as tumour grades and volumes (41-45). Our case report underlines this issue, as MRI images, despite identifying the pathological site, did not attribute a proper interpretation to the findings, in that the same lesion was also ascribable to ischemic insult, although low-grade astrocytomas are usually hyperintense on T2-weighted images (41).

${ }^{11} \mathrm{C}$-methionine PET is a sensitive imaging modality that enables a proper diagnosis of brain tumours, distinguishing 

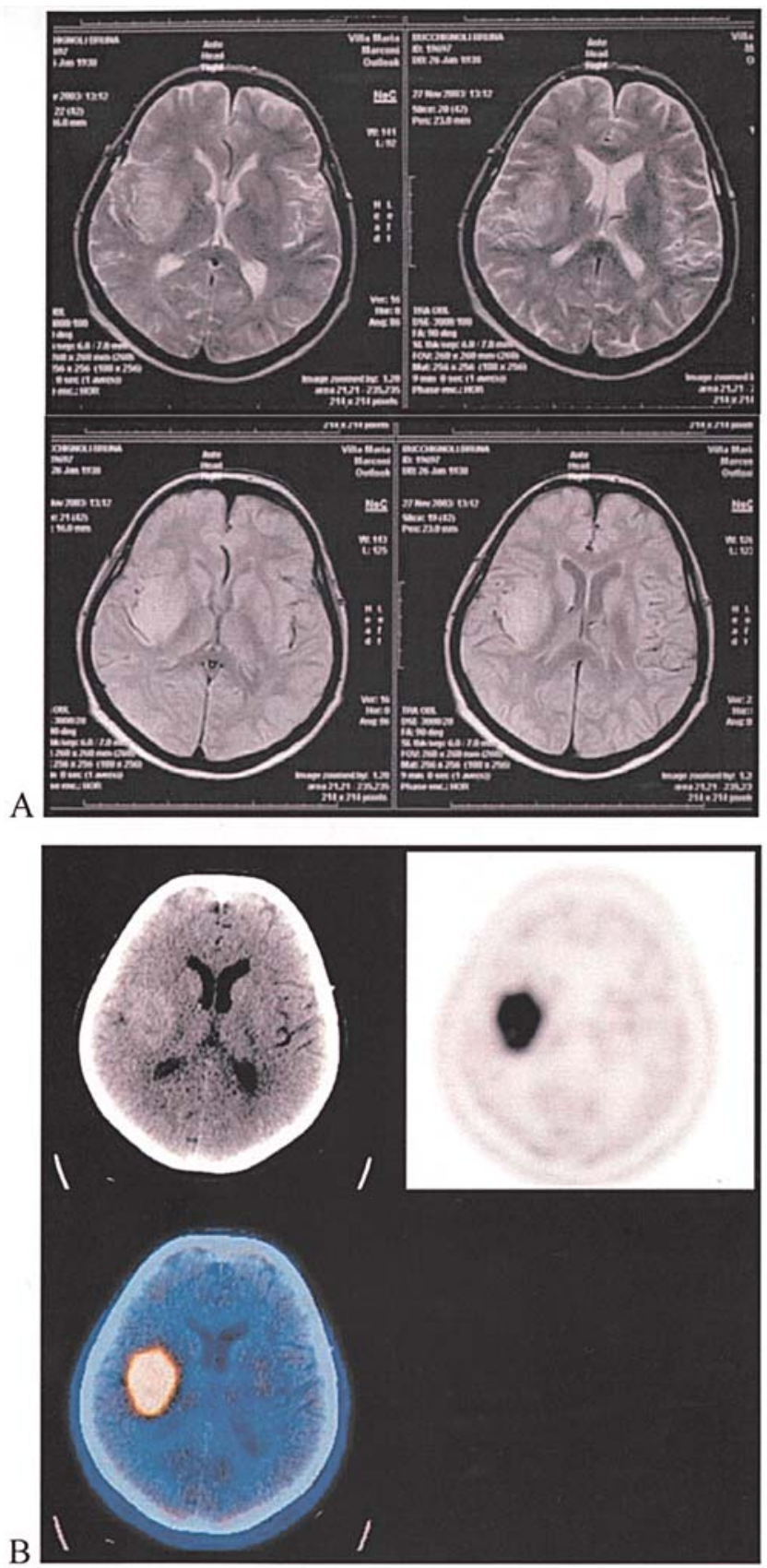

Figure 4. (A) MRI images: opercular round lesion on the right cerebral hemisphere appearing as hyperintese signal on $\mathrm{T} 2$-weighted images (upper views). (B) ${ }^{11} \mathrm{C}$-methionine PET scan: positive scan revealing an increased uptake at the reported opercular lesion.

them from other pathological situations (42-44), as well as adding valuable information for decision making in terms of surgery or stereotactic biopsy (46). Overall sensitivity of MET PET for gliomas, as estimated by several studies, seems to be around $89 \%$, with a specificity of almost $100 \%$, but with a lower rate in low-grade tumours $(65-85 \%)(42,47-49)$. Other intracranial tumours however can have a high ${ }^{11} \mathrm{C}$-methionine uptake including pituitary adenomas, ependimomas, lymphomas or brain metastases. Because of its high contrast and by applying semi-quantitative values, this method allows the identification of low- to high-grade lesions and provides an initial prognostic value $(50,51)$.

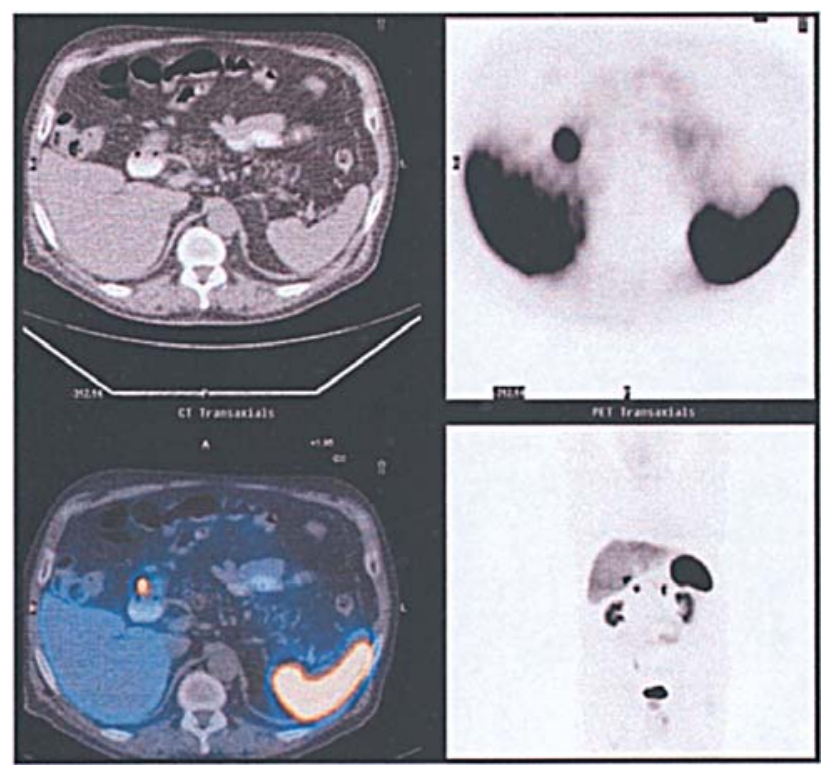

Figure 5. ${ }^{68} \mathrm{Ga}$-DOTA-NOC PET scan: single pathologic uptake interesting the duodenal wall near the head of the pancreas (SUVmax 33).

Other studies indicate a better differentiation between different tumour grades with FDG PET scan, which appears useful also for additional prognostic value $(52,53)$. These studies, however, assume an already made diagnosis of glioma. MET PET remains the proper diagnostic tool for identifying the lesion nature. At present, the role of MET PET in monitoring and predicting medical treatment response in gliomas has not been extensively studied (54-56). However, it requires more thorough investigation as the clinical studies evaluating new experimental approaches such as smallmolecule TK inhibitors of EGFr (gefitinib and erlotinib) or c-Kit (imatinib in combination with hydroxyurea) have been increasing, but the response rate is low and no molecular predictor factors of sensitivity have yet been validated (57-59).

\section{Case presentation 6}

${ }^{68} \mathrm{Ga}$-DOTA-NOC PET scan role in identifying a rare duodenal NET localization. A 76-year-old male presented at our Nuclear Medicine Division with a suspected diagnosis of neuroendocrine tumour (NET). The patient had complained of abdominal pain, diarrhea and weight loss over the previous three months. He was submitted to several imaging studies including ultrasonography and $\mathrm{CT}$, which were completely negative. We suggested a ${ }^{68} \mathrm{Ga}$-DOTA-NOC PET study to identify the unknown primary tumour. Due to its possible localization in the bowel, we administered a gastrographin swallow in order to distinguish the intestinal lumen. The examination resulted positive, revealing a single intense pathologic uptake of the tracer in the duodenal wall (SUVmax 33), although the small dimensions of the lesion $(<1 \mathrm{~cm})$ prevented the precise differentiation of the duodenal wall from the head of the pancreas (Fig. 5). Therefore a gastroduodenoscopy was performed with endoscopic selective biopsy of the duodenal wall. Histological examination confirmed the supposed diagnosis, neuroendocrine tumour, more specifically, an enteropancreatic carcinoid. 
Discussion. Neuroendocrine tumours are a heterogeneous group of neoplasms originating from pluripotent stem cells, characterized by the ability to synthetize and store various biogenic amines and peptides, and by neuro-trasmitter, neuromodulator or neuro-peptide production, and secretory granules with the absence of axons and synapses (60-62). The natural history would be the same as that of other indolent solid tumours as $30-50 \%$ of NET are non-functional neoplasms and in such cases diagnosis is confirmed later and usually due to the large tumour burden (60). The most worrisome symptoms are seen in functionally active NET, principally based on endocrine secretion, mostly due to the polypeptide somatostatin (SST). Since 1980, when it was discovered that NET cells express these polypeptide receptors, the management of this type of tumour has changed leading to the development of several diagnostic pharmacological agents as well as, later on, peptide-specific radio-receptor therapies (60). One of these is the PET radioligand ${ }^{68} \mathrm{Ga}$-DOTA-NOC, with $\mathrm{NOC}\left(\mathrm{NaI}_{3}\right.$-octreotide) being a somatostatin analogue binding almost three of the already recognised receptors (SSTR1-5) and more precisely SSTR2,3 and 5 (63). ${ }^{68} \mathrm{Ga}-$ DOTA-NOC has been used as a positron emitter tracer for the detection of NET in preliminary studies, revealing a high sensitivity in identifying neuroendocrine tumours, even of small dimensions as well as finding unknown primary tumour sites (64). Despite its vast utility in oncology, in NET, FDG PET has shown a limited utility with an apparently increased glucose uptake in the case of high grade scarcely differentiated forms but providing proper indication only for prognostic value (65-67).

Our patient had negative conventional imaging studies (CI), including CT, and despite suggestive endocrine symptoms, there was nothing else to prove an unknown primary neoplasm. Duodenal localization is quite unusual for a NET as only $10-15 \%$ of them are located in the foregut, including the stomach and duodenum. This type of tumour is mostly represented by carcinoid neoplasms (2\% of gastrointestinal tumours) as in our case report (68). In this localization we can include them in neuroendocrine enteropancreatic tumours as they originate from pancreatic islets and duodenal loop (69). In small-sized local lesions it is rather difficult to distinguish whether one or the other structure is involved, which is why conventional imaging may be negative. High tumour expression of somatostatin receptors gave an intense uptake in the ${ }^{68} \mathrm{Ga}$-DOTA-NOC PET scan, thanks to its high sensitivity ( $>95-100 \%$ ), permitting the discernment of the millimetric lesion due to the great spatial resolution of the method $(<5 \mathrm{~mm})(63,64)$. It would be beneficial to further evaluate the role of this new PET tracer in another setting such as metastatic disease, as well as in primary cancer detection. ${ }^{68} \mathrm{Ga}$-DOTA-NOC PET scan may be useful for selecting patients who can benefit from radionuclide therapy and for the assessment of therapy response.

\section{Conclusions}

Over the last few years the management of patients affected by cancer has been improved by better disease detection with molecular imaging technologies and by the introduction of new targeted drugs. Despite recent advances, everyday practice raises some practical questions such as therapeutical efficacy interpretation. Several PET compounds on a molecular basis seem to be a promising tool for noninvasive cancer evaluation but they need to be further investigated, especially for treatment assessment. Similarly, several new drugs need to be further studied in order to improve cancer patient care. In the era of molecular imaging and molecular therapies, these clinical cases highlight, firstly the urgency to define the role of new PET tracers for treatment evaluation, to develop new guidelines for the new drug efficacy assessment, and to correctly interpret the biological information obtained from new imaging technologies, and secondly, they may introduce new concepts into this field, which support the design of specific clinical trials.

\section{References}

1. Ozols RF, Herbst RS, Colson YL, et al: Clinical cancer advances 2006: major research advances in cancer treatment, prevention, and screening - a report from the American Society of Clinical Oncology. J Clin Oncol 25: 146-162, 2007.

2. Therasse P, Arbuck S, Eisenhauer E, et al: New guidelines to evaluate the response to treatment in solid tumours: European Organization for Research and Treatment of Cancer, National Cancer Institute of the United States, National Cancer Institute of Canada. J Natl Cancer Inst 92: 205-216, 2000.

3. Choi H, Charnsangavej C, Faria SC, et al: Correlation of computed tomography and positron emission tomography in patients with metastatic gastrointestinal stromal tumor treated at a single institution with imatinib mesylate: proposal of new computed tomography response criteria. J Clin Oncol 25: 1753-1759, 2007.

4. Young H, Baum R, Cremerius U, et al: Measurement of clinical and subclinical tumour response using [18F]-fluorodeoxyglucose and positron emission tomography: review and 1999 EORTC recommendations. European Organization for Research and Treatment of Cancer (EORTC) PET Study Group. Eur J Cancer 35: 1773-1782, 1999.

5. Demetri GD, von Mehren M, Blanke CD, et al: Efficacy and safety of imatinib mesylate in advanced gastrointestinal stromal tumours. N Engl J Med 347: 472-480, 2002.

6. Van Den Abbeele AD and Badawi RD: Use of positron emission tomography in oncology and its potential role to assess response to imatinib mesylate therapy in gastrointestinal stromal tumours (GISTs). Eur J Cancer 3 (Suppl 5): 60-65, 2002.

7. Antoch G, Kanja J, Bauer S, et al: Comparison of PET, CT, and dual-modality PET/CT imaging for monitoring of imatinib (STI571) therapy in patients with gastrointestinal stromal tumours. J Clin Med 45: 357-365, 2004.

8. Stroobants S, Goeminne J, Seegers M, et al: ${ }^{18}$ FDG-positron emission tomography for the early prediction of response in advanced soft tissue sarcoma treated with imatinib mesylate (Glivec). Eur J Cancer 39: 2012-2020, 2003.

9. Demetri GD, van Osteroom AT, Garret CR, et al: Efficacy and safety of sunitinib in patients with advanced gastrointestinal stromal tumour after failure of imatinib: a randomised controlled trial. Lancet 368: 1329-1338, 2006.

10. Goshen E, Davidson T, Zwas ST and Aderka D: PET/CT in the evaluation of response to treatment of liver metastases from colorectal cancer with bevacizumab and irinotecan. Technol Cancer Res Treat 5: 37-43, 2006.

11. Willet CG, Duda DG, Di Tomaso E, et al: Complete pathological response to bevacizumab and chemoradiotherapy in advanced rectal cancer. Nat Clin Pract Oncol 4: 316-321, 2007.

12. Kawada K, Murakami K, Sato T, et al: Prospective study of positron emission tomography for evaluation of the activity of lapatinib, a dual inhibitor of the ErbB1 and ErbB2 tyrosine kinases, in patients with advanced tumors. Jpn J Clin Oncol 37: 44-48, 2007.

13. Su H, Bodenstein C, Dumont R, et al: Monitoring glucose utilization by positron emission tomography for prediction of treatment response to epidermal growth factor receptor kinase inhibitors. Clin Cancer Res 12: 5659-5667, 2006.

14. Dorow DS, Cullicane C, Conus N, et al: Multitracer small-animal PET imaging of the tumor response to the novel pan-Erb-B inhibitor. Eur J Nucl Med Mol Imaging 33: 441-452, 2006. 
15. Sunaga N, Oriuchi N, Kaira K, et al. Usefulness of FDG-PET for early prediction of the response to gefitinib in non-small cell lung cancer. Lung Cancer 59: 203-210, 2008.

16. Fabio DF, Pinto C, Rojas Llimpe FL, et al: The predictive value of 18F-FDG-PET early evaluation in patients with metastatic gastric adenocarcinoma treated with chemotherapy plus cetuximab. Gastric Cancer 10: 221-227, 2007.

17. Pantaleo MA, Nannini M, Maleddu A, et al: Conventional and novel PET tracers for imaging in oncology in the era of molecular therapy. Cancer Treat Rev 34: 1510-1511, 2007.

18. Majhail NS, Urbain JL, Albani JM, et al: F-18 fluorodeoxyglucose positron emission tomography in the evaluation of distant metastases from renal cell carcinoma. J Clin Oncol 2: 3995-4000, 2003.

19. Motzer RJ, Hutson TE, Tomczak P, et al: Sunitinib versus interferon alfa in metastatic renal-cell carcinoma. N Engl J Med 356: 115-124, 2007.

20. Van den Abbeele AD, Melenevsky Y, de Vries D, et al: FDGPET imaging demonstrates kinase target inhibition by sunitinib malate (SU11248) in GIST patients resistant to or intolerant of imatinib mesylate. Eur J Cancer Suppl 3: 202, 2005.

21. De Mulder PH, Roigas J, Gillessen S, et al: A phase II study of sunitinib administered in a continuous daily regimen in patients with cytokine-refractory metastatic renal cell carcinoma (mRCC). J Clin Oncol 24: 223s, 2006.

22. George S, Casali PG, Blay J, et al: Phase II study of sunitinib administered in a continuous daily dosing regimen in patients (pts) with advanced GIST. J Clin Oncol 24: 527s, 2006.

23. De Jong IJ, Pruim J, Elsinga PH, Jongen MM, Mensik HJ and Vaalburg W: Visualization of prostate cancer with ${ }^{11} \mathrm{C}$-choline positron emission tomography. Eur Urol 42: 18-23, 2002.

24. Sutinen E, Nurmi M, Roivainen A, et al: Kinetics of $\left[{ }^{11} \mathrm{C}\right]$ choline uptake in prostate cancer: a PET study. Eur J Nucl Med Mol Imaging 31: 317-324, 2003.

25. Fazio F, Picchio $M$ and Messa $C$ : Is choline the most appropriate tracer for prostate cancer? For. Eur J Nucl Med Mol Imaging 31: 753-756, 2004.

26. Zöphel $\mathrm{K}$ and Kotzerke $\mathrm{J}$ : Is choline the most appropriate tracer for prostate cancer? Against. Eur J Nucl Med Mol Imaging 31: 756-759, 2004.

27. Farsad M, Schiavina R, Castellucci P, et al: Detection and localization of prostate cancer: correlation of ${ }^{11} \mathrm{C}$-choline PET/CT with histopathologic step-section analysis. J Nucl Med 46: 1642-1649, 2005.

28. Yoshida S, Nakagomi K, Goto S, Futatsubashi M and Torizuka T: ${ }^{11} \mathrm{C}$-choline positron emission tomography in prostate cancer: primary staging and recurrent site staging. Urol Int 74: 214-220, 2005.

29. Reske SN, Blumstein NM, Neumaier B, et al: Imaging prostate cancer with ${ }^{11} \mathrm{C}$-choline PET/CT. J Nucl Med 47: 1249-1254, 2006.

30. Scher B, Seitz M, Albinger W, et al: Value of ${ }^{11} \mathrm{C}$-choline PET and PET/CT in patients with suspected prostate cancer. Eur $\mathbf{J}$ Nucl Med Mol Imaging 34: 45-53, 2007.

31. Picchio M, Landoni C, Messa C, et al: Positive ${ }^{11} \mathrm{C}$-choline and negative $\left[{ }^{18} \mathrm{~F}\right] \mathrm{FDG}$ with positron emission tomography in recurrence of prostate cancer. AJR Am J Roentgenol 179: 482-484, 2002.

32. Picchio M, Messa C, Landoni C, et al: Value of $\left[{ }^{11} \mathrm{C}\right]$ cholinepositron emission tomography for re-staging prostate cancer: a comparison with $\left[{ }^{18} \mathrm{~F}\right]$ fluorodeoxyglucose-positron emission tomography. J Urol 169: 1337-1340, 2003.

33. Cimitan M, Bortolus R, Morassut S, et al: ${ }^{18} \mathrm{~F}$-choline PET/CT imaging for the detection of recurrent prostate cancer at PSA relapse: experience in 100 consecutive patients. Eur J Nucl Med Mol Imaging 33: 1387-1398, 2006.

34. Hurwitz HI, Fehrenbacher L, Hainsworth JD, et al: Bevacizumab in combination with fluorouracil and leucovorin: an active regimen for first-line metastatic colorectal cancer. J Clin Oncol 23: 3502-3508, 2005.

35. Sandler A, Gray R, Perry MC, et al: Paclitaxel-carboplatin alone or with bevacizumab for non-small-cell lung cancer. $\mathrm{N}$ Engl J Med 355: 2542-2550, 2006.

36. Miller KD, Chap LI, Holmes FA, et al: Randomized phase III trial of capecitabine compared with bevacizumab plus capecitabine in patients with previously treated metastatic breast cancer. J Clin Oncol 23: 792-799, 2005.

37. Cai W, Chen X: Multimodality imaging of vascular endothelial growth factor and vascular endothelial growth factor receptor expression. Front Bioscience 12: 4267-4279, 2007.
38. Chen W, Delaloye S, Silverman DH, et al: Predicting treatment response of malignant gliomas to bevacizumab and irinotecan by imaging proliferation with $[18 \mathrm{~F}]$ fluorothymidine positron emission tomography: a pilot study. J Clin Oncol 25: 4714-4721, 2007.

39. De Geus-Oei LF, van Laarhoven HW, Visser EP, et al: Chemotherapy response evaluation with FDG-PET in patients with colorectal cancer. Ann Oncol 19: 348-352, 2008.

40. Davis FG, Kupelian V, Freels S, et al: Prevalence estimates for primary brain tumors in the United States by behaviour and major histology groups. Neuro-Oncology 3: 152-158, 2001.

41. Brown PD, Wald JT, McDermott MW, et al: Oncodiagnosis panel: 2002. Optic nerve glioma or optic nerve meningioma. Radiographics 23: 1591-1611, 2003.

42. Singhal T, Narayanan TK, Jain V, et al: (11)C-L-methionine positron emission tomography in the clinical management of cerebral gliomas. Mol Imaging Biol 10: 1-18, 2008.

43. Hustinx R, Pourdehnad M, Kaschten B and Alavi A: PET imaging for differentiating recurrent brain tumours from radiation necrosis. Radiol Clin North Am 43: 35-47, 2005.

44. Wong TZ, Van der Westhuizen GJ and Coleman RE: Positron emission tomography imaging of brain tumours. Neuroimaging Clin N Am 12: 615-626, 2002.

45. Kondziolka D, Lunsford LD and Martinez AJ: Unreliability of contemporary neurodiagnostic imaging in evaluating suspected adult supratentorial (low-grade) astrocytoma. J Neurosurg 79: 533-536, 1993.

46. Gumprecht H, Grosu AL, Souvatsoqlou M, et al: 11C-Methionine positron emission tomography for preoperative evaluation of suggestive low-grade gliomas. Zentralbl Neurochir 68: 19-23, 2007.

47. Herholz K, Hölzer T, Bauer B, et al: 11-C-methionine PET for differential diagnosis of low-grade gliomas. Neurology 50: 1316-1322, 1998.

48. Chung JK, Kim YK, Kim SK, et al: Usefulness of 11C-methionine PET in the evaluation of brain lesions that are hypo- or isometabolic on 18 F-FDG PET. Eur J Nucl Med Mol Imaging 29: 176-182, 2002.

49. Braun V, Dempf S, Weller R et al: Cranial neuronavigation with direct integration of (11)C methionine positron emission tomography (PET) data - results of a pilot study in 32 surgical cases. Acta Neurochir 144: 777-782, 2002.

50. Huang MC, Shih MH, Chung WY, et al: Malignancy of intracerebral lesions evaluated with 11C-methionine-PET. J Clin Neurosci 12: 775-780, 2005.

51. Kim S, Chung JK, Im SH, et al: 11C-methionine PET as a prognostic marker in patients with glioma: comparison with 18F-FDG PET. Eur J Nucl Med Mol Imaging 32: 52-59, 2005.

52. Di Chiro G: Positron emission tomography using [18F] fluorodeoxyglucose in brain tumours. A powerful diagnostic and prognostic tool. Invest Radiol 22: 360-371, 1987.

53. Padma MV, Said S, Jacobs M, et al: Prediction of pathology and survival by FDG PET in gliomas. J Neurooncol 64: 227-237, 2003.

54. Galldiks N, Kracht LW, Burghaus L, et al: Use of 11C-methionine PET to monitor the effects of temozolomide chemotherapy in malignant gliomas. Eur J Nucl Med Mol Imaging 33: 516-524, 2006.

55. Tang BN, Sadeghi N, Branle F, De Witte O, Wilker D, Goldman S: Semi-quantification of methionine uptake and flair signal for the evaluation of chemotherapy in low-grade oligodendroglioma. J Neurooncol 71: 161-168, 2005.

56. Herholz K, Kracht LW and Heiss WD: Monitoring the effect of chemotherapy in a mixed glioma by C-11-methionine PET. J Neuroimaging 13: 268-271, 2003.

57. Rich JN, Reardon DA, Peery T, et al: Phase II trial of gefitinib in recurrent glioblastoma. J Clin Oncol 22: 133-142, 2004.

58. Haas-Kogan DA, Prados MD, Tihan T, et al: Epidermal growth factor receptor, protein kinase $\mathrm{B} / \mathrm{Akt}$, and glioma response to erlotinib. J Natl Cancer Inst 97: 880-887, 2005.

59. Dresemann G: Imatinib and hydroxyurea in pretreated progressive glioblastoma multiforme: a patient series. Ann Oncol 16: 1702-1708, 2005.

60. Prasad V, Fetscher S and Baum RP: Changing role of somatostatin receptor targeted drugs in NET: Nuclear Medicine's view. J Pharm Pharmaceut Sci 10: s321-s337, 2007.

61. Vinik AI, Woltering EA, O'Dorisio TM et al: Neuroendocrine Tumors: A Comprehensive Guide to Diagnosis and Management. Inter Science Institute, USA, 2006.

62. Rufini V, Calcagni ML and Baum RP: Imaging of neuroendocrine tumors. Semin Nucl Med 36: 228-247, 2006. 
63. Wild D, Schmitt JS, Ginj M, et al: DOTA-NOC, a high-affinity ligand of somatostatin receptor subtypes 2,3 and 5 for labelling with various radiometals. Eur J Nucl Med Mol Imaging 30: 1338-1347, 2003.

64. Baum RP, Niesen A, Leonhardi J, et al: Receptor PET/CT imaging of neuroendocrine tumors using the Ga-68 labelled, high affinity somatostatin analogue DOTA-1-NaI3-octreotide (DOTA-NOC): clinical results in 327 patients. Eur J Nucl Med Mol 32 (Suppl 1): 54-55, 2005.

65. Eriksson B, Bergström M, Orlefors $\mathrm{H}$, et al: Use of PET in neuroendocrine tumors. In vivo applications and in vitro studies. Q J Nucl Med 44: 68-76, 2000.

66. Pasquali C, Rubello D, Sperti C, et al: Neuroendocrine tumor imaging: can 18F-fluorodeoxyglucose positron emission tomography detect tumors with poor prognosis and aggressive behavior? World J Surg 22: 588-592, 1998 .
67. Belhocine T, Foidart J, Rigo P, et al: Fluorodeoxyglucose positron emission tomography and somatostatin receptor scintigraphy for diagnosing and staging carcinoid tumours: correlations with the pathological indexes p53 and Ki-67. Nucl Med Commun 23: 727-374, 2002.

68. Oberg K and Eriksson B: Nuclear medicine in the detection, staging and treatment of gastrointestinal carcinoid. Best Pract Res Clin Endocrinol Metab 19: 265-276, 2005.

69. Mignon M: Natural history of neuroendocrine enteropancreatic tumours. Digestion 62 (Suppl 1): 51-58, 2000. 